\title{
CORRESPONDENCE
}

\section{Unscientific Issues}

SIR,-It is easy to sympathize with the editor of Nature $(239,182 ; 1972)$ because it is obviously very difficult to define precisely the limits of discussion in a general scientific journal. Certainly the criterion that "scientists are more affected than other groups of people" seems reasonably satisfactory, much more so than the original definition on the basis of the official or unofficial nature of the decision (Nature, 238, 57; 1972). Unfortunately, in practice, this does not seem to be the criterion.

Under this criterion, a comment on the murder of Professor Aharon Katchalsky is obviously valid, but a more general condemnation of terrorism seems not to be. And letters such as that of Dr Pryor (Nature, 239, 179; 1972) are clearly invalid, if it were not already invalid on the grounds of simple logic. What, after all, is the use of anti-personnel weapons on "military" targets if not "carefullyplanned, purposeful, braggartly and wanton murder of random civilians"?

Moreover we are unable to understand how, using this criterion, Nature has refused to publish the statement of the Varenna Summer School on the History of Physics. This statement by a body of scientists concerns the use of modern scientific techniques in Vietnam, and clearly poses to scientists their responsibilities in carrying out research which may improve these weapons. Clearly this is an issue which concerns scientists more than others.

Nature cannot squirm out of this by asking if it can be seriously held that the innovations of military technology are in themselves a cogent reason why the United States should now withdraw from its involvement in Vietnam. This is not the claim, as the editor knows well. What is important is that scientists are responsible for the uses to which their research is put. They are also responsible for the applications of the research of other scientists. From this point of view, scientists who are opposed to the war in
Vietnam can only support the action of those who have demanded explanations from Gellmann, Drell and Wheeler of their participation in the Jason Division of the Institute for Defence Analysis. And certainly discussion of these issues is important in a general scientific journal.

Yours faithfully,

IAN G. MORGAN

C. GORIDIS

G. Gombos

Centre de Neurochimie du Centre National de la Recherche Scientifique,

11 rue Humann,

67085 Strasbourg Cedex

\section{Porphyria}

SiR,--Recently McDonagh (Nature, 237, 297; 1972) pointed out that MatthewsRoth and associates demonstrated the effectiveness of $\beta$-carotene in protecting patients with erythropoietic protoporphyria (EPP) against the photosensitizing action of protoporphyrin-IX. In the interest of assigning proper credit and priority, it should be mentioned that, as noted by Matthews ${ }^{1}$, Kesten ${ }^{2}$ reported the successful therapeutic use of carotene on a photosensitive patient in 1951. Kesten selected carotene because its absorption spectrum was similar to the action spectrum which elicited the patient's symptoms. It is of interest that Kesten's description of the patient enumerated several of the classic symptoms of EPP, ten years before the disease entity was clearly defined ${ }^{3}$.

\section{Yours faithfully,} JOHN A. JOHNSON RAMON M. Fusaro

Department of Dermatology, University of Nebraska Medical Center, Omaha, Nebraska 68105

1 Matthews, M. M., Nature, 203, 1092 (1964). 2 Kesten, B. M., Arch. Derm., 64, 221 (1951). 3 Magnus, I. A., Jarrett, A., Prankerd, T. A. J., and Rimington, C., Lancet, ii, 448 (1961).

\section{Madness or Badness ?}

SiR,-Unfortunately, I have been unable to read all the correspondence dealing with the murder of Professor Katchalsky at Tel Aviv airport, but a few of the points raised by Dr. William A. Pryor in his letter (Nature, 239, $179 ; 1972)$ require comment.

As regards the Vietnam war, the argument that American soldiers who kill civilians do so either by mistake or because of some mental derangement is too much of a simplification (in the case of the My Lai massacre I find it totally unacceptable).

And how does one distinguish between the pardonable crimes of American soldiers, who, we are told, act as a result of a "sick aberration", and the unpardonable crimes of "demented" though "true-believing" Palestinian guerrillas?

Finally, although Vietnam is a country in the turmoil of civil war and in that sense the scene of a military conflict, the Palestinian terrorists regard the whole world as a battlefield as long as their aims are unachievable.

Yours faithfully, DAVID R. JENKINS

1000 Berlin 51, Genfer Strasse 63, West Berlin

\section{Dingle Jingle}

SIR,-

There was a Professor called Dingle

Who made physicists' nerve endings tingle.

His travelling clocks

Caused grave mental blocks

In those who thought time should stay single.

Yours faithfully, JOHN LETTS

83 West Side,

Clapham Common,

London SW4

\section{Obituary}

\section{Professor James Norman Davidson}

Professor Norman Davidson, Gardiner Professor of Biochemistry in the University of Glasgow since 1948, died on September 11 at the age of 61. Dux of George Watson's College in Edinburgh, he won a scholarship in medicine to the University of Edinburgh where he took a BSc with 1st Class Honours in Chemistry in 1934 and an MB ChB with Honours in 1937. Even by this time his interests had come to lie in the labora- tory and in 1937 he was awarded a Carnegie Fellowship to work at the Kaiser Wilhelm Institut für Zellphysiologie in Berlin under the direction of Otto Warburg. On his return to Britain in 1938 he was appointed to a lectureship in Biochemistry at the University of St 